\title{
Neuro-occlusal rehabilitation in the treatment of temporomandibular joint dysfunction, cervicalgia, bruxism, and tinnitus: A case report
}

Denise Barbosa $^{1}$, Luiz de Carvalho ${ }^{2}$, Sibele Bete ${ }^{1}$, Laura Bana ${ }^{1}$, and Fausto Berzin ${ }^{1}$

${ }^{1} \mathrm{FOP}$

${ }^{2}$ Luiz Eduardo Pinto de Carvalho

July 30,2020

\begin{abstract}
Here we report different disorders associated in a single case. TMJ and neck pain, bruxism and tinnitus symptom were reported. After verifying the causes and define effects with high technology tool, therapeutic was conducted with occlusal splint DOOPE@[?] and selective wear based on Neuro-Occlusal Rehabilitation getting better in all symptoms.
\end{abstract}

\section{Hosted file}

NOR_in_the_treatment_of_TMJ_dysfunction_ cervicalgia_bruxism_and_tinnitus.pdf available at https://authorea. com/users/347594/articles/473239-neuro-occlusal-rehabilitation-in-thetreatment-of-temporomandibular-joint-dysfunction-cervicalgia-bruxism-and-tinnitus-acase-report
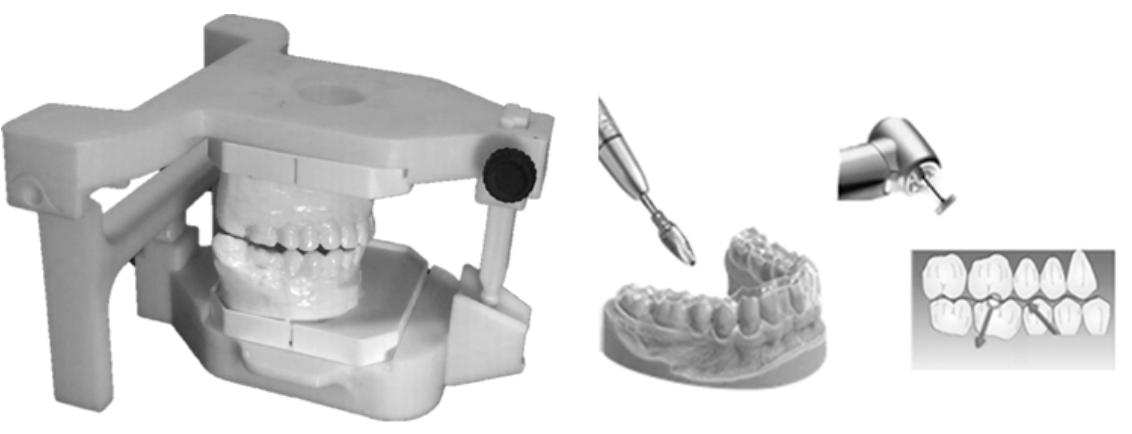